\title{
KNOWLEDGE OF DENTAL PRACTITIONERS TOWARDS EMERGENCY MANAGEMENT OF AVULSED TOOTH IN PUNJAB
}

\author{
Simran Pal Singh Bindra ${ }^{1}$, Sunila Sharma ${ }^{2}$, Ajay Chhabra ${ }^{3}$, Varun Jindal ${ }^{4}$, Damanpreet ${ }^{5}$, Kamal Nabhi ${ }^{6}$ \\ ${ }^{1}$ PG Student, Department of Conservative Dentistry \& Endodontics, Bhojia Dental College \& Hospital, Bhud, Himachal Pradesh, India \\ ${ }^{2}$ Senior Lecturer, Department of Pediatric \& Preventive Dentistry, Bhojia Dental College \& Hospital, Himachal Pradesh, India \\ ${ }^{3}$ Professor \& Head, Department of Conservative Dentistry \& Endodontics, Bhojia Dental College \& Hospital, Himachal Pradesh, India \\ ${ }^{4}$ Reader, Department of Conservative Dentistry \& Endodontics, Bhojia Dental College \& Hospital, Himachal Pradesh, India \\ ${ }^{5}$ Reader, Department of Conservative Dentistry \& Endodontics, Bhojia Dental College \& Hospital, Himachal Pradesh, India \\ ${ }^{6}$ PG Student, Department of Conservative Dentistry \& Endodontics, Bhojia Dental College \& Hospital, Himachal Pradesh, India
}

\begin{abstract}
\begin{tabular}{r|r} 
ABSTRACT \\
ABTS
\end{tabular}
Dental avulsion is characterized by the complete displacement of the tooth from its socket, with damage to the periodontal ligament, cementum, alveolar bone, gingival and pulp tissues. The ideal treatment for an avulsed permanent tooth is its immediate replantation into the socket. However, in spite of its recognized therapeutic value, clinical experience has shown that immediate replantation rarely occurs due to factors associated to the accident itself, complex damage to the recipient site, or simply lack of knowledge or confidence of the general population and even professionals about Replantation procedures. The present study was carried out with an aim to assess the level of knowledge of emergency management of avulsed teeth among 209 Dental practitioners in the state of Punjab. The received questionnaires were analysed for the responses. The data showed that the knowledge of dental practitioners in the state was not up to date and efforts should be made to carry out various education programs for the same.
\end{abstract}

Key words: Traumatic Dental Injuries, Avulsion, Replantation, Questionnaire

\section{INTRODUCTION}

\section{Traumatic Dental Injuries} constitute one of the most common oral health problems nowadays. Major cause of the steep rise in TDIs in recent years is the rapid increase in automobile accidents and sports injuries. Traumatic dental injuries may vary in severity from mild concussion injuries that do not loosen the offended tooth to avulsion injuries. ${ }^{1}$ An Avulsion injury is the most serious of all dental injuries. Dental avulsion is characterized by the complete displacement of the tooth from its socket, with damage to the periodontal ligament, cementum, alveolar bone, gingival and pulp tissues. $^{2}$
It accounts for $0.5 \%$ to $16 \%$ of traumatic injuries in the permanent dentition and $7 \%$ to $21 \%$ of injuries in the primary dentition. ${ }^{3}$ The prognosis of a replanted tooth and its maintenance on the dental arch for the longest possible time depends on the viability of the periodontal ligament (PDL) cells remaining on root surface, integrity of root cementum and minimal bacterial contamination which are conditions directly related to the extraalveolar time, type of storage after avulsion and root surface alterations. The ideal treatment for an avulsed permanent tooth is its immediate replantation into the socket. However, in spite of its recognized therapeutic value, clinical experience has shown that immediate 
replantation rarely occurs due to factors associated to the accident itself, such as presence of extensive lifethreatening injuries, complex damage to the recipient site, patient's emotional condition at the moment of trauma, or simply lack of knowledge or confidence of the general population and even professionals about replantation procedures. ${ }^{4,5}$

Every dentist must be well prepared to meet these emergencies. It is incumbent upon the dentist to preserve the vitality of injured teeth whenever possible and to restore them skillfully to their original appearance, without producing additional trauma (or) endangering the integrity of the teeth. In a nutshell, the presentation of avulsion incidences in a dental clinic is not rare and a thorough knowledge of its management is must. The present study was conducted with an aim to assess the level of knowledge of emergency management of avulsed teeth among Dental practitioners in the state of Punjab.

\section{MATERIALAND METHODS}

The private dental hospitals and clinics of Punjab were randomly selected. Out of 314 dental practitioners contacted, only 209 showed willingness to participate in the study. These participants were either running their practice independently or were employed in the hospitals or clinics. A questionnaire was distributed among them which contained 8 close ended questions (multiple choice questions). The questions were framed to cover all the important aspects of managing patient with avulsed tooth in dental office. The number of questions wee kept to the minimum to increase the response rate. It was made sure that all the questions were answered in front of the investigator. Confidentiality was maintained as it did not require name and contact number of the participants. Data was collected and analysed.

\section{RESULTS}

The results obtained from the study showed variable response regarding knowledge of dentists about avulsed teeth. 198(94.7\%) participants out of 209 responded that they would replant an avulsed permanent tooth in most of the situations. At the same time, almost equal number of respondents (93.8\%) answered that they will not replant avulsed primary teeth. Only $18(8.6 \%)$ participants were found to have attended any education program regarding management of traumatic injuries to teeth, though 92(44\%) dental practitioners had encountered at least one case of avulsion in their career. When asked Responses to other questions asked are depicted in Table 1 and 2.

Table 1: Percentage distribution of responses of recommended transport media of a avulsed tooth from the site of injury to the dental office and critical time for reimplantation of avulsed tooth.

\begin{tabular}{|l|l|}
\hline \multicolumn{2}{|l|}{ Recommended Transport Media } \\
\hline Hanks balanced salt solution & $80.3 \%$ \\
\hline Milk & $11.9 \%$ \\
\hline Saliva /Saline solution & $5.7 \%$ \\
\hline Others & $1.91 \%$ \\
\hline Critical time for the replantation \\
\hline Within 20 mins & $71.7 \%$ \\
\hline $20-60$ mins & $23.6 \%$ \\
\hline $1-2$ hour & $4.7 \%$ \\
\hline
\end{tabular}

Table 2: Percentage distribution of responses regarding splinting of reimplanted avulsed tooth

\begin{tabular}{|l|l|}
\hline \multicolumn{2}{|l|}{ Type of splint used } \\
\hline Rigid & $84.2 \%$ \\
\hline Flexible & $13.4 \%$ \\
\hline Anyone & $2.4 \%$ \\
\hline Splinting Period & $3.8 \%$ \\
\hline Two weeks & $22.9 \%$ \\
\hline Four weks & $32.5 \%$ \\
\hline Six weeks & $39.2 \%$ \\
\hline More than six weeeks
\end{tabular}




\section{DISCUSSION}

Numerous studies have been reported in the literature whereby knowledge of parents, teachers and general dental practitioners concerning the management of avulsed teeth had been investigated thoroughly. ${ }^{6-9}$ The present study also aimed at assessing the knowledge of dental practitioners about the management of avulsed teeth.

The questionnaire used in the present study consisted of closed ended and direct questions. The prognosis of avulsed tooth is very much dependent on the actions taken at the place of accident and promptly after the avulsion. Replantation is in most situations the treatment of choice, but cannot always be carried out immediately. There are also individual situations when replantation is not indicated (e.g., severe caries or periodontal disease, non-cooperating patient, severe medical conditions (e.g., immune suppression and severe cardiac conditions) which must be dealt with individually. ${ }^{10}$ Replantation may successfully save the tooth, but it is important to realize that some of the replanted teeth have lower chances of long-term survival and may even be lost. ${ }^{10,11}$ In the present study, majority of participants showed adequate knowledge as far as emergency treatment of avulsed tooth was concerned. About $95 \%$ of respondents answered that they would replant an avulsed permanent tooth in most of the situations and will refrain from replanting primary tooth which is in accordance with the current guidelines and recommendations of the IADT. ${ }^{12}$

However, it has been recommended not to replant teeth with open apices that remained in dry conditions for more than $1 \mathrm{~h} .{ }^{12,13}$ Other studies showed even a higher tendency for dentists to replant a permanent tooth in every case. ${ }^{14}$ It seems that the tendency of general dentists to save teeth at any cost may have increased their willingness to replant teeth in every case. $^{15}$
Preparation of the root is dependent on the maturity of the tooth (open vs. closed apex) and on the dry time of the tooth before it was placed in a storage medium. ${ }^{16}$ A dry time of $60 \mathrm{~min}$ is considered the point where survival of root periodontal ligament cells is unlikely. ${ }^{17}$ The results of our study showed that majority of the participants, $150(71.7 \%)$ said that the critical time for the replantation is within 20 minutes, $49(23.6 \%)$ said it to be 20 to 60 minutes and a very less $10(4.7 \%)$ said it is one to two hours.

Yet another important factor is the storage of the tooth during handling of the tooth from the time of injury till the tooth is replanted back into its socket. An Ideal storage medium would be one that is capable of preserving the viability, Mitogenicity, and clonogenic capacity of the damaged PDL in order to facilitate repopulation of the denuded root surface thereby preventing further root resorption. Also, the ideal storage media should be readily available for use in emergency situations. In accordance to Krasner, Hank's balanced salt solution is the best solution for storing avulsed teeth. ${ }^{18,19}$ In the present study, $80.3 \%$ of the respondents knew that HBSS is the optimal storage medium to preserve the tooth. This indicated good knowledge among the practitioners with regards to preserve the tooth, however only $14 \%$ had this storage media available in their dental office.

For the question regarding the treatment of an avulsed tooth before replantation; in case of short or prolonged extra alveolar dry time, only $34.4 \%$ said that it is not same for both cases, thus the rest may be treating the two similarly. In teeth with prolonged extra alveolar periods, where periodontal ligament can be assumed as necrotic, it has been suggested that root surface be treated with fluoride solution $(2.4 \%$ sodium fluoride phosphate acidulated at $\mathrm{pH}$ 5.5) for 20 minutes prior to replantation. The incorporation of fluoride ions in the cementum layer has been found to yield root surface resistant to resorption. ${ }^{20}$ 
The current guidelines for dentists in managing avulsed permanent teeth (excluding root fractures and alveolar fractures) recommend splinting periods as follows: the International Association of Dental Traumatology, IADT: up to 2 weeks American Academy of Pediatric Dentistry, AAPD: 7 days, the American Academy of Endodontics ${ }^{21,24}$, AAE: 7-14 days, the Royal College of Dental Surgeons England $^{22,23}$, RCDSE, 7-10 days.?

However, the results of our study showed that majority of dental practitioners recommended rigid splinting $(84.2 \%)$ for more than six weeks(39.2\%), which is contradictory to the ideal time recommended. Splinting technique plays a pivotal role in the success of replantation of avulsed tooth and therefore a lot of work needs to be done for upadating the knowledge of the dental practitioners regarding splinting. ${ }^{25}$

The analysis of the results obtained revealed that the knowledge of dental practitioners in Punjab regarding management of avulsed teeth is not up to the mark. It was disappointing to find out that in spite of scarcity of experience and knowledge of managing this TDI, none of the dentist had ever attended any education program regarding the same.

The present study had few limitations. It was not recorded that whether the respondent was a General Dental Practitioner or a specialist. At the same time, the year of working experience of dentist was not taken into consideration. Knowledge of managing avulsion injuries among the dentist may be higher in those with greater duration of working experience as well as among the specialists. Also, there was lack of control group and the willingness to participate in the survey was quite low among the dental practitioners.

\section{CONCLUSION}

Within the limitations of the study, it is concluded that the dentists of Punjab do not have adequate knowledge regarding management of avulsed teeth. Keeping in mind the effective management of TDI, education programs in this field are highly recommended and the participation of all practitioners should be made mandatory.

\section{REFERENCES}

1. Andreasen JO, Andreasen FM. Textbook and Colour atlas of dental trauma. 3rd edition, Porto Alegre Art Med Editor. $769 \mathrm{p}$

2. Andreasen JO, Andreasen FM. Avulsions. In: Andreasen JO, Andreasen FM, Editors. Textbook and Color Atlas Of Traumatic Injuries To The Teeth. Copenhagen: Munksgaard; 1994. P. 383-425.

3. Bogen G, Chandler NP. Vital Pulp Therapy In Ingle's Endodontics. Ingle JI, 6th ed, Hamilton, Ontario, Canada: BC Decker; 2008: 1310-1319

4. Caglar E, Sandalli N, Kuscu OO, Durhan MA. Pisiriciler R, Calıskanea. Viability of Fibroblasts in a Novel Probiotic Storage Media Dent Traumatol 2010; 26:383-387

5. Cardos LC, Poi WR, Panzarini SR, Sonoda CK, Rodrigues TS, Manfrintm. Knowledge of Firefighters With Special Paramedic Training of the Emergency Management of Avulsed Teeth. Dent Traumatol 2009; 25:58-63

6. Walker A, Brenchley J. It's a knockout: Survey of the management of avulsed teeth. Accid Emerg Nurs 2000;8(2): $66-70$

7. Caldas AF Jr, Burgos ME. A retrospective study of traumatic dental injuries in a Brazilian dental trauma clinic. Dent Traumatol 2001;17(16):250-3

8. Holan G Shmueli Y. Knowledge of physicians in hospital emergency rooms in Israel on their role in cases of avulsion of permanent incisors. Int J Paediatr Dent 2003;13:13-9

9. Pacheco LF, Filho PFG, Letra A, Menezes R, Villoria GEM, Ferreira SM. Evaluation of the knowledge of the treatment of avulsions in elementary schoolteachers in Rio de Janeiro, Brazil. Dent Traumatol 2003;19:76-8

10. Martins Wd, Portela V. Tooth Replantation After Traumatic Avulsion: 27- Years Follow Up. Dental Traumatology 2004; 20:101-105

11. Donaldson M, Kinirons Mj. Factors Affecting The Time Of Onset Of Resorption In Avulsed And Replanted Incisor Teeth In Children. Dental Traumatology 2001; 17:205-209

12. Flores MT, Andreasen JO, Bakland LK, Feiglin B, Gutmann JL, Oikarinen K. International Association of Dental 
Traumatology. Guidelines for the evaluation and management of traumatic dental injuries. Dent Traumatol 2001;17:193-8

13. American Association of Endodontists. Recommended guidelines for the treatment of traumatic dental injuries. Chicago: American Association of Endodontists; November 2004

14. Stokes AN, Anderson HK, Cowan TM. Lay and professional knowledge of methods for emergency management of avulsed teeth. Endod Dent Traumatol 1992;8:160-2

15. Cohenca N, Forrest JL, Rotstein I. Knowledge of oral health professionals of treatment of avulsed teeth. Dental Traumatology 2006; 22: 296-301

16. Belladonna Fg, Poly A, Teixeira Jms, Fidel Sr. Avulsion Of Permanent Teeth With Open Apex: A Systematic Review Of Literature. Revista Sul-Brasileira de Odontologia 2012; 9(3): 309-15

17. Zhou Y, Yusheng Li, Mao L, Openg H. Periodontal Healing By Periodontal Ligament Cell Sheets In A Teeth Replantation Model. Archives OfOral Biology 2012; 57:169-176

18. Ashkenazi M, Marouni M. In Vitro Viability, Mitogenicity And Clonogenic Capacities Of Periodontal Ligament Fibroblasts After Storage In Four Media Supplemented With Growth Factors. Dental Traumatology 2001; 17:27-35
19. Andreasen JO. The effect of extra-alveolar period and storage media upon periodontal and pulpal healing after replantation of mature permanent incisors in monkeys. Int J Oral Surg $1981 ; 10: 43-51$

20. Panzarini SR, Gulinelli JL, Poi WR, Sonoda CK, Pedrini D, Brandini DA.Treatment Of Root Surface In Delayed Tooth Replantation: A Review Of Literature. Dent Traumatol 2008; 24:277-282

21. Pavek DI, Radtke PK. Post-Replantation Management of Avulsed Teeth: An Endodontic Literature Review. Gen Dent 2000; 48:176-81

22. Gregg TA, Boyd DH.Uk National Clinical Guidelines In Pediatric Dentistry.Treatment Of Avulsed Permanent Teeth In Children. Int J Pediatric Dent 1998;8:75-81

23. American Academy Of Pediatric Dentistry. Clinical Guideline On Management Of Acute Dental Trauma. Pediatr Dent 2005; 27:120-5

24. American Association of Endodontists. Recommended Guidelines of The American Association Of Endodontists For The Treatment of Traumatic Dental Injuries. 2004 http://www.Aae.Org/Dentalpro/Educationalresources/Guidel ines. Html [Accessed On 15 June 2014]

25. Bindra SS, Khurana JJ, Chhabra A, Sharma S. Spliniting ad its correlates: Areview and update. BFUDJ 2014,5;10:17-21 
Questionnaire regarding knowledge of managing avulsed teeth

Qualification:

Years of Practice:

Q.1 Can an avulsed permanent tooth be replanted in all cases?

General Practitioner/ Endodontist

a. Yes

b. No

Q.2 What is the critical time for the replantation of an avulsed tooth?

a. Within 20 mins

b. 20-60 mins

c. 1-2 hour

d. Not sure

Q.3 What is the optimal storage media?

a. Hank's balanced salt solution

b. Milk

c. Patient's saliva

d. Saline solution

e. Via span

f Others

Q.4 Do you think any cleaning procedure is necessary before replantation?

a. Yes

b. No

Q.5 Is the pre- treatment of an avulsed tooth before replantation same in

a. Yes case of short or prolonged extra alveolar dry time?

b. No

Q.6 Type of splint used is

a. Rigid

b. Flexible

c. Anyone

d. Others

Q.7 Splinting period is for $\mathrm{s}$

a. Two weeks

b. Four weeks

c. Six weeks

d. Others

Q.8 What is the intra-canal medication used during root canal treatment?

a. Zinc oxide eugenol

b. Calcium hydroxide

c. Antibiotic paste

d. Others

Q.9 Should primary tooth be replanted?

a. Yes

b. No

Q.10 Have you ever attended any education program regarding management of traumatic injuries to teeth?

a. Yes

b. No 